\title{
From Stroboscope to Dream Machine: A History of Flicker-Induced Hallucinations
}

\author{
B.C. ter Meulen ${ }^{a} \quad$ D. Tavy ${ }^{a} \quad$ B.C. Jacobs ${ }^{b}$ \\ a Department of Neurology and Neurophysiology, Haga Teaching Hospital, The Hague, and \\ ${ }^{b}$ Department of Neurology, Erasmus Medical Centre, Rotterdam, The Netherlands
}

\section{Key Words}

Electroencephalogram • Photic driving • Hallucinations • Beat Generation

\begin{abstract}
When early neurophysiologists, like William Grey Walter (1910-1977), started using intermittent photic driving in electroencephalography, they were struck by a wide range of visual hallucinations that were reported. In current neuroscience, the phenomenon is used mainly to model hallucinations that are related to altered neuronal activity between the thalamus and the visual cortex, such as the Charles Bonnet syndrome. However, during the psychedelic 1960s, Brion Gysin (1916-1986), a painter and a poet, became interested in the hallucinations and designed his own stroboscope or dream machine, as a means for spiritual enlightenment. This article traces back the history of flicker-induced hallucinations from the early use of stroboscopes in neurophysiology to the dream machine.

Copyright $\odot 2009$ S. Karger AG, Base
\end{abstract}

\section{Introduction}

Intermittent photic stimulation is performed as part of the routine electroencephalogram (EEG) in order to establish alpha wave reactivity (occipital driving response) and test for a possible convulsive reaction or 'photoparoxysmal response' in patients with photosensitive epilepsy. Photosensitive epilepsy is typically a diag- nosis of childhood and adolescence that probably affects about $8 \%$ of healthy children [1]. William Grey Walter (1910-1977) and other pioneers of the EEG also noted another remarkable effect of stroboscopic light, as some individuals reported visual hallucinations. Though the hallucinations have gained relatively little interest within the laboratory, they received more than average attention from the members of the 1960s underground, the Beat Generation, who even started manufacturing their own stroboscopes. Here, we describe how an ordinary tool in the neurophysiology department became a means for spiritual enlightenment or a dream machine.

\section{Revelation by Flicker}

The history of flicker-induced hallucinations goes back to the pre-scientific era. There is a popular story, for example, in which Catherine de Medici had Nostradamus sitting on her rooftop. The prophet would subsequently receive visions by watching the sun with his eyes closed, quickly interrupting the light with his spread hand [2]. Fact or fiction? One of the first official accounts was made in 1819 by Purkinje, who saw various patterns like crosses, stars and spirals, when waving his hand between his eyes and a gaslight in a way similar to Nostradamus [3]. His contemporary Brewster produced similar images by running alongside evenly spaced vertical railings, thereby directing his eyes towards the sun which was behind them. Brewster, a physicist from Scotland, likened the checkerboard patterns he provoked to the

\section{KARGER}

Fax +4161306 1234 E-Mail karger@karger.ch www.karger.com

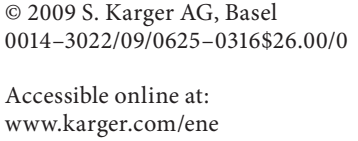

B.C. ter Meulen

Department of Neurology and Neurophysiology

Leyweg 275

NL-2545 The Hague CH (The Netherlands)

Tel. +31 70210 0000, Fax +31 2102 189, E-Mail b.termeulen@erasmusmc.nl 
'brightest tartan' [4]. Further investigations were made by Helmholtz in his Physiological Optics, who coined the term 'shadow patterns' [5].

The phenomenon went largely forgotten until the invention of the EEG by Berger in the 1920s. The effects of flash light on the brain suddenly became of interest, as they could be translated into changing patterns of electric activity. Using an automobile headlight shining through a rotating wheel with spokes, Adrian and Matthews in 1934 showed that by means of flicker (frequencies within the $8-12 \mathrm{~Hz}$ alpha range and up) 'a coordinated beat' could be imposed on the alpha rhythm of a test person sitting in front of the lamp with his or her eyes closed [6]. A limitation to their method, however, was that in order to increase the frequency of the flicker, the wheel had to turn faster thereby shortening the duration of the flashes. The problem of the inconstant flashes was overcome by the use of the first electronic stroboscopes shortly after the Second World War. Then, the visual hallucinations came into the laboratory. In his book The Living Brain, Walter wrote about:

'whirling spirals, whirlpools, explosions ... In testing a device to study epilepsy we had stumbled on one of those natural paradoxes which are the surest sign of a hidden truth' [7].

Interestingly enough, the chapter he used to describe the effects of stroboscopic light was named 'Revelation by Flicker', which certainly must have struck the artists we are soon to discuss. A colourful description of the hallucinations comes from the poet Margiad Evans, who is cited by Walter:

'Lights like comets dangled before me, slow at first and then gaining a fury of speed and change, whirling colour into colour, angle into angle. They were all pure ultra unearthly colours, mental colours, not deep visual ones. There was no glow in them but only activity and revolution' [7].

What is the exact nature of the hallucinations? In the 1950s, Costa distinguished three categories: autoscopic, geometric and hallucinatory images [8]. The autoscopic images consisted of 'ramifications of retinal veins' and 'hexagonal cells of the choroid'. The geometric patterns included radial figures, sometimes stripes or waves. Some individuals experienced complex hallucinations, for example, horses or spiders. At the Psychological Laboratory in Cambridge, UK, Smythies undertook several largescale studies. He divided the stroboscopic images into dark phase and bright phase patterns. Bright phase patterns arise on binocular stimulation with the eyes closed and within the visual field of the stimulated eye in case of monocular stimulation. Dark phase patterns also arise from monocular stimulation but are seen with the unstimulated eye [9]. The bright phase is characterized by geometric patterns, either dominated by straight lines (e.g. crosses, diamonds, or triangles) or curved lines (e.g. circles, vortices or fingerprint patterns) [10]. Sometimes complex designs or images are reported. The recurring geometric figures are also known as 'form constants' and may also be elicited by other means, such as psychedelic drugs, sleep (hypnagogic hallucinations) or near death [11]. The dark phase hallucinations on the contrary tend to be more irregular. Smythies distinguished several categories: (1) amorphous, featuring two colours, usually red and green, swirling around like oil on water; (2) small objects moving, rather than colours, that some compared to an 'ant heap' or 'an aerial photo of a city'; (3) stationary patterns like ink-blots or leaves; (4) watery patterns; (5) design patterns resembling wallpaper; (6) animate patterns like a movie; (7) scenes or landscapes such as fish in an aquarium or grass and forests [12].

Smythies [13] put forward several explanations for the hallucinations. First, there is the hypothesis that the patterns represent retinal structures such as vessels or pigmented cells. This explanation may account for only a small part of the hallucinations (the autoscopic hallucinations from Costa's study). The second hypothesis is based upon the original idea by Walter that the alpha waves represent a visual scanning mechanism and that the hallucinations are caused by interference between flicker and the scanning mechanism [14]. The forms of the images might represent different scanning rasters, for example scanning with parallel or radiating lines. The third hypothesis is that the images are created by spontaneous activity of cortical neurons having no clue of the stimulus they are exposed to and make 'their own hypotheses'. The fourth hypothesis is that the images are caused by excitation of specific circuits between the retinal and cortical neurons (patterned activity). Ffytche [15] elaborated on the latter hypothesis by supposing that the images represent a shift in thalamocortical activity from a tonic mode to a burst mode. In a tonic mode, retinal signals are faithfully transmitted to the cortex (the greater the retinal input the greater the output to the cortex), whereas in a burst mode the input and output become partly dissociated, which gives rise to widespread hallucination-related activation. Central to Ffytche's idea is that hallucinations are not caused by altered activity in specific brain areas (a 'topological' explanation) but by altered connectivity between different areas (a 'hodological' explanation). 


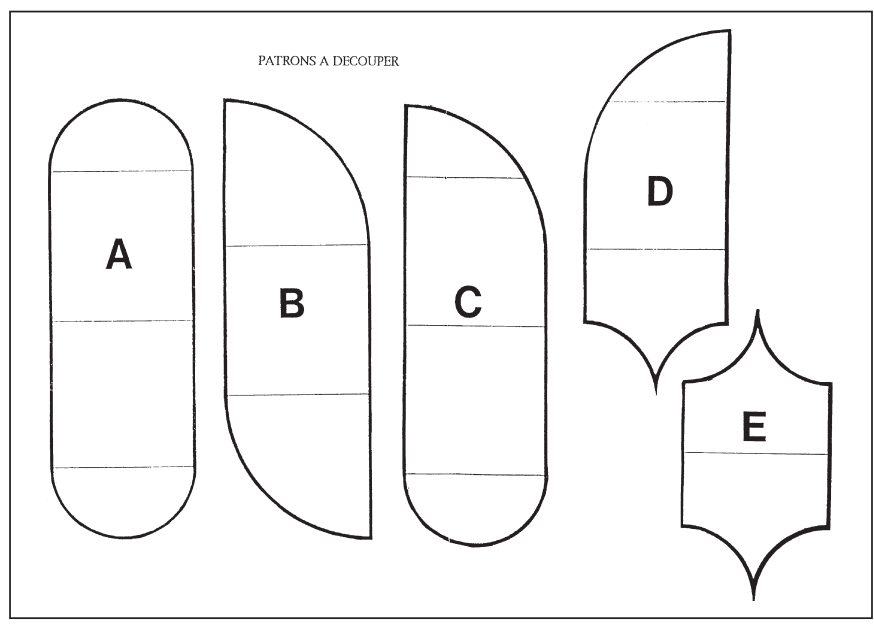

Fig. 1. Dream machine building plan.

\section{The Dream Machine}

'This book is intended for general reading, for those who are interested in themselves and in other creatures', Walter dedicated The Living Brain to a broad audience [16]. One of his curious readers was the writer William Burroughs (1914-1997), who probably stumbled upon the book on one of his queries through the bookstores and libraries of Paris, searching for the strange and the occult. There he read about the hidden powers of the flicker.

Burroughs was a wanderer who lived alternately in New York City, Tanger (Morocco) and Paris. He was a first-hour Beatnik. It is not an easy task to define the Beatnik, as being Beat is all about non-conformity and individuality. How to discern a common thread? For his article 'The anatomy of a beatnik', McDarrah, a photographer who extensively documented the Beat Generation, took the street, only to end up with numerous definitions of negation and protest: 'we're the innocents', 'it's a movement of protest', 'the world lies in the hands of the nonconformists', 'all my life I've been rebelling', 'I'm anti-materialistic' [17]. The Beat Generation was a counterculture, a way of living probably best caught in Kerouac's autobiographic novel On the Road. The main characters of the books are two youngsters, Sal and Dean, who are continuously on the move, away from home, and the relative stability of a family and a job. They are going all through America looking for distraction [18]. Among the kicks the Beats pursued there were various mind-enhancing drugs including lysergic acid (LSD), psilocybin and

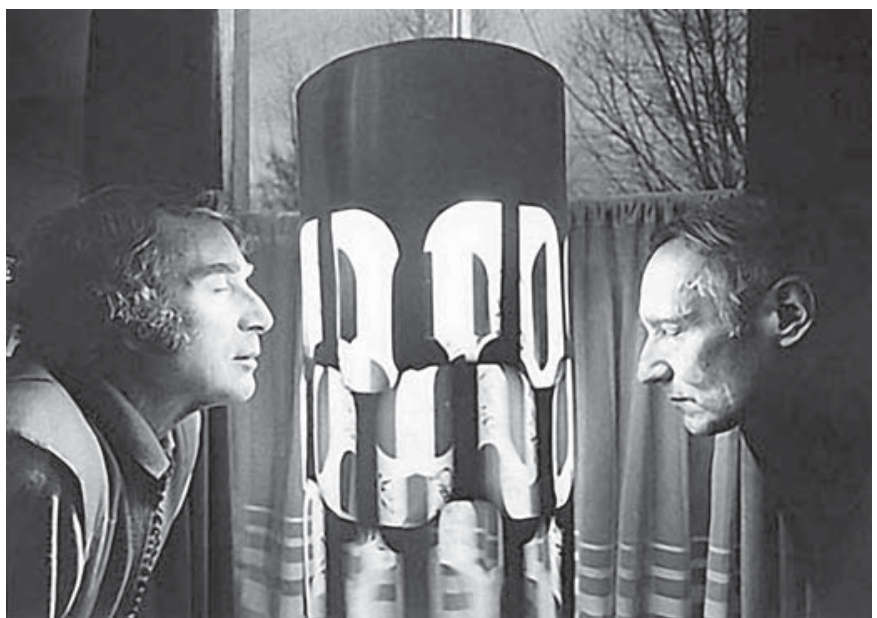

Fig. 2. Brion Gysin (left) and William Burroughs facing the dream machine.

peyote. Therefore, it should be no surprise that the stroboscope was eagerly welcomed as a tool for enlightenment.

The flicker phenomenon reminded Burroughs of a story he had recently been told by his soul mate Brion Gysin (1916-1986). At the time they both inhabited a cheap hotel in 9, rue Git Le Coeur, a small alley in the middle of the Latin Quarter of Paris. The place has been known as the Beat Hotel ever since [19]. Gysin was a man with many skills; he was a painter, a poet, a calligrapher, a musician and a cook, all in one lifetime. On December 21,1958 , as his diary reports, he had been travelling on a bus in southern France. He had fallen asleep, leaning with his head against the window pane. On passing by a row of trees, sunlight came flickering through and Gysin started to hallucinate:

'an overwhelming flood of intensely bright patterns in supernatural colours exploded behind my eyelids: a multi-dimensional kaleidoscope whirling out through space. The vision stopped abruptly when we left the trees. Was that a vision?' [20].

Gysin knew by experience what neurophysiologists like Walter were talking about. Burroughs was able to hand him the theoretical framework.

The next step was to manufacture a stroboscope for private use. Gysin persuaded one of his friends, Ian Sommerville (1940-1976), to make one. Sommerville, who was originally a mathematician, came up with a simple but effective design. He made a cardboard cylinder with holes on a fixed distance (fig. 1) that was placed on a 78 
rpm turntable with a light bulb within. When the turntable starts spinning the light will come out with a regular frequency within the $8-12 \mathrm{~Hz}$ alpha range, similar to a laboratory stroboscope. They named it the dream machine, which would be changed into Dreamachine for marketing goals. Soon the first Beatniks showed up at their place to sit in front of the machine and have their share in the experience (fig. 2). Burroughs wrote down his personal account in The Ticket That Exploded [21]. Their mutual friend, the poet Allen Ginsberg wrote about the Dreamachine:

'I looked into it - it sets up optical fields as religious and mandalic as the hallucinogenic drugs - it's like being able to have jewelled biblical designs and landscapes without taking chemicals' [22].

And so it was: the Dreamachine simply provided them with a 'drugless high', though all agreed that the combination of psychedelic drugs and flicker worked best.

Gysin foresaw a great future for his device, eventually replacing the television set in every home. He got a patent for 'a procedure and apparatus for the production of artistic sensations' [23] and made connections, for example with the Philips Corporation, who sent a representative to the Beat Hotel. There was no deal, however. The company saw no commercial potential, and a common and deeply rooted fear of photosensitive epilepsy might have been involved as well. As a result, the Dreamachine never came into mass production, despite all of Gysin's best attempts.

\section{Epilogue}

During the 1980s, Gysin vanished into anonymity like many of the magic tricks he and Burroughs had been performing. He died little known, except for the various artists he had influenced like the rock singer Iggy Pop or the English singer and songwriter Marianne Faithfull. He regained attention only recently: Geiger wrote a biography [20], the story of Gysin's life was filmed as FlicKeR in 2008 and a giant retrospective of his work opened in London the same year. Are these mere echos of the past or are there any current applications of stroboscopic induced brain activity?

In neuroscience, hallucinations are still hard to model. Animal models will not tell us anything about the experience the 'subjects' go through, and experiments with psychedelic drugs like LSD are rather controversial from an ethical stance. The studies from Ffytche have shown that the stroboscope is a friendly and reliable tool for the induction of visual images by altering neuronal activity in and between the thalamocortical circuits [15]. A change in thalamocortical activity has also been associated with a variety of neuropsychiatric disorders ('thalamocortical dysrythmias'), including the Charles Bonnet syndrome (CBS) [24]. The CBS consists of complex visual hallucinations that typically occur when there is an inadequate stimulus to the visual system. Patients generally suffer from eye conditions like macular degeneration and are aware that the phenomena are not real. Especially in the dark they experience a range of hallucinations that are very similar to the ones induced by the stroboscope [25]. As a result, the stroboscopic hallucinations can be used to study the underlying mechanisms of the CBS and possible therapeutic interventions, like medication. Note that the well-known hallucinations of Parkinson's disease or schizophrenia have a different nature and involve different brain areas, including the serotonergic raphe nuclei and the cholinergic tegmental nucleus of the brainstem [26].

Another application comes from the field of brain function training [27]. In 1958, Kamiya, a psychologist from Chicago put one of his students in a dark room with EEG electrodes on his head. The subject had to guess whether he was generating an alpha rhythm over the occipital areas of his brain when Kamiya sounded a tone. In the beginning he was able to guess correctly only half of the time. However, after a couple of days the graduate was scoring right almost every time Kamiya pushed the button. The subject learnt to 'be in alpha', a state that turned out to be profoundly relaxing. From that moment, alpha neurofeedback took a start [28]. Photic driving might have an equal effect on well-being by imposing 'a coordinated beat' on the brain within the alpha range, an idea that still needs further investigation.

In summary, the 'flicker phenomenon' took off in the early days of science mainly as a curiosity. The stroboscope subsequently turned into a dream machine, and during the 1960s it became a genuine cult object. Today stroboscopes can be used to model the complex mechanisms underlying specific (not all) visual hallucinations and might contribute to the state of bliss and happiness the Beatniks were looking for.

\section{Acknowledgement}

We thank Nik Sheehan, film maker and director of FlicKeR, for critically reading an earlier version of the manuscript. 


\section{References}

1 Doose H, Gerken H: Photosensibilität. Genetische Grundlagen und klinische Korrelationen. Neuropädiatrie 1973;4:162-171.

2 Gysin B, Wilson T: Here To Go: Planet R-101. London, Quartet, 1985.

3 Purkinje J: Beiträge zur Kenntniss des Sehens in subjektiver Hinsicht. Prague, Vetterl, 1819.

4 Wade N: A Natural History of Vision. Cambridge, MIT Press, 2000.

5 Helmholtz H: Physiological Optics. Rochester, Optical Society of America, 1925.

$\checkmark 6$ Adrian ED, Matthews BHC: The Berger rhythm: potential changes from the occipital lobes in man. Brain 1934;57:355-385.

7 Walter WG: The Living Brain. London, Gerald Duckworth \& Co., 1953, pp 64-65.

$>8$ Costa AM: L'effeto geometrico-cromatico nella stimolazione intermittente della retina ad occhi chiusi. Arch Psicol Neurol Psichiatr 1953; 14:632-635.

-9 Brown GR, Gebhard JW: Visual field articulation in the absence of spatial stimulants gradients. J Exp Psychol 1948;38:188-200.

10 Smythies JR: The stroboscopic patterns. II. The phenomenology of the bright phase and after-images. Br J Psychol 1959;50:305-324.
11 Klüver H: Mescal and Mechanisms of Hallucinations. Chicago, University of Chicago Press, 1966.

12 Smythies JR: The stroboscopic patterns. I. The dark phase. Br J Psychol 1959;50:106116.

13 Smythies JR: The stroboscopic patterns. III. Further experiments and discussion. $\mathrm{Br}$ Psychol 1960;51:247-255.

14 Walter WG: The Living Brain. London, Gerald Duckworth \& Co., 1953, pp 69-70.

15 Ffytche DH: The hodology of hallucinations. Cortex 2008;44:1067-1083.

16 Walter WG: The Living Brain. London, Gerald Duckworth \& Co., 1953, p xi.

17 McDarrah FW, McDarrah TS: The anatomy of a beatnik; in Kerouac and Friends. New York, Thunder Mouth Press, 2002, pp 177188.

18 Kerouac J: On the Road. London, Penguin, 2002.

19 Miles B: The Beat Hotel. New York, Grove Press, 2001.

20 Geiger J: Nothing Is True Everything Is Permitted. The Life of Brion Gysin. New York, The Disinformation Company, 2005, p 160.
21 Burroughs W: The Ticket That Exploded. New York, Grove Press, 1994.

22 Ginsberg A: Letter to Timothy Leary; in Geiger J: Chapel of Extreme Experience. New York, Soft Skull Press, 2003, p 58.

23 Geiger J: Chapel of Extreme Experience. New York, Soft Skull Press, 2003, p 66.

24 Llinas RR, Ribary U, Jeanmonod D, Kronberg E, Mitra PP: Thalamocortical dysrhythmia: a neurological and neuropsychiatric syndrome characterized by magnetoencephalography. Proc Natl Acad Sci USA 1999;96: 15222-15227.

25 Ffytche DH: Visual hallucinations and the Charles Bonnet syndrome. Curr Psychiatry Rep 2005;7:168-179.

26 Manford M, Andermann F: Complex visual hallucinations. Clinical and neurobiological insights. Brain 1998;121:1819-1840.

27 Warren J: The Head Trip. Adventures on the Wheel of Consciousness. Toronto, Vintage Canada, 2007, pp 218-262.

28 Nowlis DP, Kamiya J: The control of electroencephalographic alpha rhythms through auditory feedback and the associated mental activity. Psychophysiology 1970;6:476-484. 